\title{
Transition into teaching - The lived experience of De La Salle Lipa education graduates: A hermeneutic phenomenology
}

Macatangay, Jose C.

De La Salle Lipa, Philippines (jose.macatangay@dlsl.edu.ph)

Received: 1 September 2014 Available Online: 13 October 2014
Revised: 29 September 2014 DOI: $10.5861 /$ ijrse.2014.897

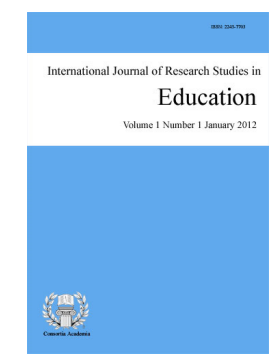

ISSN: 2243-7703 Online ISSN: 2243-7711

OPEN ACCESS

\section{Abstract}

The first year of teaching is the deciding factor whether a new teacher will embrace this noble profession or quit at the end of the school year. No matter how equipped a beginning teacher is, there are intricacies and challenges that arise especially in the first few months of being in the battleground called classroom. Studying the lived experience of new teachers can serve a two-fold purpose: it can be therapeutic on their part and it can help improve the experiential learning courses of undergraduate students. Using a hermeneutic phenomenological design, this study aims to explore on the meaning of lived experience of 20 De La Salle Lipa Education graduates batch 2014 employed in various schools within and outside the province of Batangas. Following Lichtman's (2006) six-step process of Codes, Categories and Concepts, key themes illuminated from the study: the real classroom is an entirely different world, the first step to teaching is really full of challenges, some positive personal traits are essential to survive teaching, teaching competencies are crucial in the practice of the teaching profession and Lasallian education plays an important role in creating a positive attitude towards teaching and in facilitating their transition to it. Results will be important in enhancing current practices in teaching pedagogy courses and in designing interventions necessary for curriculum improvement.

Keywords: hermeneutic phenomenological analysis; lived experience; DLSL education graduates; pedagogy, interventions 


\section{Transition into teaching - The lived experience of De La Salle Lipa education graduates: A hermeneutic phenomenology}

\section{Introduction}

"New teachers are the lifeblood of the profession".

This thought was articulated by Bluestein (2010) in the first part of her book "Becoming a Win-Win Teacher". The enthusiasm, optimism, creativity and fresh perspective were identified by Bluestein (2010) to be the qualities a new teacher has to bring to "keep the spirit of the school alive". She further elaborated that for new teachers to succeed in the teaching profession, they need to adopt a win-win approach which is "being able to think, plan to make decisions considering the students and other members of the school community". Some examples of win-win strategies she mentioned are: establishing authority without disempowering students, avoiding frustrating and self-defeating behaviors, focusing on the positive aspects of student's behavior and work, accommodating students' needs for respect, acceptance and belonging and reducing stress and burnout among others. Bluestein considered teaching a "people business" since it primarily deals with people aspects of work like connecting and challenging students which may dampen the spirit of new teachers if they do not adopt a win-win stance in the practice of the profession. She argued that no matter how extensive the pre-service experience of a new teacher is, their tendency to be de-motivated is high when they are already teaching because of their "unpreparedness for the realities" of actual teaching. The transition to teaching demands, a change in perspective and an adjustment to a totally new environment are some of the difficulties encountered by the beginning educators.

In corroboration of Bluestein's thoughts about the win-win approach to teaching, Thompson (2009) offered some self-help for classroom success of new teachers. Some of these are adopting a problem-solving approach when things are difficult, doing routine tasks efficiently, taking things one day at a time, using problems as opportunities to become better teachers and leaving the problems at school while bringing home successes.

Green (2010) discussed how author and teacher W. Michael Kelley compared teaching the first class based on what was learned in college to be similar to "being asked to swim across the Atlantic Ocean with nothing more than those little inflatable armbands". College provides a good basis for the beginning teachers but there are intricacies not tackled in college that may come along the way so there is really a need for new teachers to be prepared. Because of the extreme demands and responsibilities of teaching with some unexpected twists and turns, Kelly forewarned the new teachers "You will stay afloat, but you will swallow a lot of water along the way".

Marchesani (2007) explained that the first month of school is crucial so there is a need for beginning educators to take advantage of every bit of experience that will occur inside and outside the classroom since they will mold them to become successful teachers. She stressed on the importance of the character a teacher needs to possess along with the pedagogical skills. Merchesani identified the six traits of an effective teacher. They are those who are excited about what they are teaching, show fairness in dealing with students, manifest a positive attitude about teaching and learning, prepared, sincere and know they are not perfect and set high expectations for their students. For a classroom to be dynamic, she offered some teaching activities known as pacing, sponge activities, technology, diverse instruction and learning modalities.

According to Ball and Forzani (2010), there are three key domains of professional preparation which include knowledge of content, curriculum of practice and approaches and settings. They stressed the fact that teachers need a special kind of knowledge that will enable them to articulate their thoughts in simple ways understandable to the learners. However, the authors noticed the lack of a "well-defined curriculum of practice" for future 
teachers. The authors argued that unlike other professions, prospective teachers are not prepared to do some of the "core tasks of teaching like conducting effective class discussions and diagnosing a child's reading difficulty". Likewise, the authors emphasized the need for student teaching to be "carefully supervised and structured" by a supervisor who gives feedback and serves as coach to novice teachers whose teaching skills need to be honed.

The difference between a new teacher and an experienced one in terms of dimensions of teaching practices was found by Maat and Zakaria (2010) in their article about Mathematics teachers' reflection on their teaching practices. Reflection was operationally defined in the study as "the teacher's interpretation of teaching practices". Interview and observation were the instruments used by the researchers to gather data from the two respondents: one who has been teaching for 12 years and the other teacher having only one and half year of teaching experience. One point of difference between the two teachers is on preparation where the experienced teacher tries to know the background of her students while the novice teacher practices the questions she will ask in class and prepares her visual aids. In line with the problems encountered in class, the experienced teacher met passive and lazy students while the new teacher failed to deal with student's attitude. Sadly, the study disclosed that the teacher participants were able to reflect on their practices in class but they admitted they did not know how to deal with those classroom-related matters.

Using hermeneutic phenomenology, Wallace and Irons (2010) studied the lived experience of 15 teachers at public schools across Texas. The respondents were grouped as novice, competent and expert. Through the seven-essay prompts analyzed using Colaizzi's (1978) method for qualitative data analysis, the study found that public school teachers have varying needs as they advance in their teaching career. The overarching themes uncovered from the respondents "collective conceptualizations" were bittersweet, self-confident and teach each child for the novice, competent and expert teachers respectively. Teaching is "bittersweet" for the novice teachers because they have wanted to become teachers, they enjoy what they are doing yet the profession is not free from difficulties to hurdle. Based on the lived experience of the competent teachers, they claimed to be "self-confident" to teach their class. This competence stems from their "mastery of the ability to teach the group of students who were their class". Among the experienced teachers, their world view of teaching was synthesized as "teach each child". Because of their professional preparation, the experienced teachers are passionate about teaching, committed to excellence and set high expectations for their students' academic performance. The study proposed that teachers' trainings need to be varied in order to address the diverse needs of the different groups of teachers.

To explore the lived experience of online educators, De Gagne and Walters (2010) adopted the process of hermeneutic phenomenological design "to examine the concepts considered important by online educators, to determine the knowledge, skills and attitudes perceived essential by the respondents, to differentiate between face-to-face instruction and online teaching, to identify the strategies used to facilitate active learning and the issues faced in online teaching and finally to share their thoughts on what academic leaders can do to help them become active successful online teaching".

Eleven participants participated in the study through interview and e-mail. Data were analyzed using Lichtman's (2006) three C's of analysis: Codes, Categories and Concepts following a six-step process. Five key themes surfaced from the responses of the participants: "online teaching offers flexibility and convenience, online teaching is time-consuming and labor intensive, strong communication skills are essential, much of online teaching is learner-centered and online teaching requires continuing education and training". The study revealed that concepts of learner-centeredness and social presence were considered "highly essential components in teaching online". Equally important was the understanding of andragogy which is the method of teaching adult learners in online teaching environment. Experiential learning was identified by the participants as a strategy needed to promote active learning. A little difference was found between on-ground and online teaching on the area of ethical and legal issues. A well-designed mentoring system was the administrative support the research participants expected from the administration. 
Buetel and Croswell (2012) delved into the readiness of a group of entry education students to teach as they leave the university and enter the teaching profession. Through a qualitative interpretive study, 34 graduating students from the Graduate Diploma in Education course in Southeast Queensland, Australia served as respondents for the study. Three emerging themes were revealed from the data obtained through a questionnaire: "seek further canonical skills to take into the classroom, acknowledge the contribution of Field Experience and desire ongoing professional learning". The study concluded that the respondents acknowledged the contributions of their field experience in their formal teacher education and that they "sought further professional learning opportunities in the canonical skills of teaching".

At the end of every academic year, De La Salle Lipa confers diplomas to graduating Bachelor of Secondary Education (BSE) and Bachelor of Elementary Education students in various fields of specializations. Very eager to find their first teaching job, these graduates take the opportunity to apply at some private schools while waiting for graduation. Fortunately, some of the Education graduates are employed even before graduation while others need to wait after graduation. After leaving the portals of the institution, nothing is heard about how these graduates are performing in their respective schools. This paper is a seminal work in the institution in line with the lived experience of the new batch of graduates who are employed in different private schools.

Readers of this paper particularly educators will learn from the study that much remains to be done as they prepare students to the real world of teaching. Since hermeneutic as a method carries a "moral force", educators have moral responsibility to their students by knowing their educational experiences. Doing so, they can facilitate students' learning.

\section{Theoretical Review}

\subsection{Hermeneutic Phenomenology}

The study was anchored on hermeneutic phenomenology which is a variant of qualitative research. Kafle (2011) in his article "Hermeneutic Phenomenological Research" exploited Smith's definition of hermeneutic phenomenology as a "research methodology aimed at producing rich textual descriptions of the experiencing of selected phenomena in the life world of individuals that are able to connect with all human beings collectively". Further, he said that hermeneutic or the art of interpretation necessitates the understanding of the stories told by people about their experiences. Kakkori (2009) discussed how Heidegger showed the link between hermeneutics and phenomenology known as hermeneutical phenomenology and defined as "the research of the meaning of the Being as a fundamental ontology". Kafle (2011) concluded in his article that hermeneutic phenomenology as a method "within the interpretive design" aims to unleash the understanding of a phenomenon in order to have a better view of the world. As applied in the study, hermeneutic phenomenology was used to unearth the lived experience of the respondents through their written accounts. The world view of the new teachers was expressed in themes in order to have a full grasp of the essential meaning of their lived experience.

Five Dreyfus Model Stages - The study adopted the "Five Dreyfus Model Stages" which posits that changes occur as people acquire and master new skills. The first stage in the Dreyfus model is Novices defined as having "little or no previous experience in the skill area". Novices have short-term goal which they want to accomplish right away. They can be susceptible to confusion and are not knowledgeable in responding to mistakes. Because of their little experience, they have difficulty figuring out if their actions will be favorable. The second stage in the model is advanced beginners who attempt at breaking from the fixed rule a bit but find it difficult to find an instant solution to problems. Advance beginners do not see the big picture yet because they would like to see patterns through their previous experiences. In contrast with the advanced beginners, the Competent in the third stage have acquired the skill of troubleshooting problems and have started to solve unique dilemmas which they have not encountered before. People at this level are those in the leadership role through their initiative and resourcefulness. At the fourth stage classified as Proficient, the practitioners apply maxims to the "situation at 
hand". Unlike the novice who considers a maxim as a recipe, the proficient have enough experience learned from others which they use for self-reflection. At the end of the line of Dreyfus model is the Expert. These are the authors of books and articles and the modern wizards. The experts rely on intuition and not from reason. They know the details to "focus on" and which ones to "ignore".

\section{Methods}

\subsection{Research Questions}

The aim of this qualitative research is to explore on the lived experience of De La Salle Lipa's Education graduates of batch 2014. In order to prove on the meaning and essence of the participants' lived experience, the following research questions were scrutinized in the study:

$>\quad$ What are the differences between being a practice teacher and being a real classroom teacher as identified by the participants?

$>\quad$ What are the challenges encountered by the participants during their first month of teaching?

$>\quad$ What are the personal traits considered essential by the participants in their practice of the teaching profession?

$>\quad$ What are the teaching competencies deemed important by the novice teachers?

$>\quad$ What do the participants think about the role played by their Lasallian education in developing a positive attitude towards teaching?

\subsection{Research Participants and Data}

The participants of the study were 20 graduates of De La Salle Lipa's Education Department batch 2014 who at the conduct of the study were attending the Licensure Examination for Teachers (LET) review sessions for the first semester of the current school year. The breakdown of the respondents is as follows: four (4) BSE-Social Science, four (4) BEED, two (2) Special Education, three (3) BSE-Math and seven (7) BSE-English. They are all employed in several schools in Lipa City and nearby cities and municipalities in Batangas province. One respondent is teaching in a private school in Alabang.

Data were obtained from the responses of the participants in the 10 open-ended questions or prompts that they answered. The three C's of analysis known as Coding, Categorization and Concepts advanced by Lichtman (2006) was used in the study in order to draw "meaningful concepts or themes from the raw data". Lichtman (2006) broke down the process into six steps such as: initial coding, revising initial coding, developing an initial list of categories, modifying initial list, revising categories and subcategories and moving from categories to concepts. Below is the explanation of each step as it is applied in the study:

Step 1: Initial coding. According to Lichtman (2006), an initial code can be a word, a phrase, or the respondents' own words. After a careful and close reading and scrutiny of the responses, brief phrases served as basis for the initial coding.

Step 2. Revisiting initial coding. In this part of the analysis, the researcher followed Lichtman's advice of collapsing and renaming the codes from large chunks of information. Redundancies were removed and consistency was observed.

Step 3. Initial listing of categories. After modifying the codes, they were organized into categories such as $a$ world of difference, the challenges of teaching, handling disciplinary problems, knowledge, attitudes and skills of a teacher, competencies of a new teacher, skills the Education department needs to provide, and significance of 
Macatangay, J.

Lasallian education.

Step 4. Modifying the initial list. A rereading of the initial list was done in this part and decision was made in terms of considering the importance of categories and the need to combine some of them. As applied in the study, the category "knowledge, attitudes and skills" was reduced to "personal traits of a new teacher". The item "skills the Education Department needs to provide" was subsumed by "competencies needed by a new teacher". The category "handling disciplinary problems" was lumped into the "Lasallian education".

Step 5: Revisiting categories. In this step, initial codes were already collapsed and redundancies were eliminated. The researcher's judgment about inclusion and exclusion came into the picture. The following categories were decided to form part of the collective conceptualizations: a world of difference, challenges of teaching, traits considered important by a new teacher, competencies deemed essential by a novice teacher and the role of Lasallian education.

Step 6: From categories to concepts. It is at this stage where the researcher decided on the themes which were derived from the categories. For Lichtman (2006), five to seven concepts would suffice to emerge from a set of data. The following key themes of concepts were used for the study: (1) The real classroom is an entirely different world, (2.) The first step to teaching is really full of challenges, (3.) Some positive personal traits are essential to survive teaching, (4).Teaching competencies are crucial in the practice of the teaching profession and (5). Lasallian education plays an important role in creating a positive attitude towards teaching.

\subsection{Reliability and Limitations of the Research}

To determine the reliability of results, two inter-raters who were faculty members of the Education Department were asked to evaluate the themes formulated based on the rubrics given to them following Lichtman's (2006), three C's of analysis discussed in the paper. The limitation of the paper is in terms of its conclusive claim about the lived experience of the participants. The generalizability of the paper is confined only to the school under study.

\section{Results}

\subsection{The themes illuminated from the study}

Theme 1: The real classroom is an entirely different world. The respondents undeniably valued their internship training but contrasted their experiences from the real classroom and described it to be full of responsibilities which include making right decisions, handling not just one but several classes and being assigned as club moderator. One participant wrote: “I'm no longer a student who tries to teach". During internship, a student teacher is fully guided by a cooperating teacher who is there to help so everything seems easy and concerns are limited to preparing lesson and delivering it. In the real classroom, according to the participants, there are more requirements to comply with, pressures to handle and expectations to live up to. The presence of a cooperating teacher lessens disciplinary problems while in the real classroom, students tend to misbehave. The respondents claimed that in internship, everything seems to be scripted and planned while in the real classroom, anything can happen which may be beyond the control of the teacher. As regards classroom tasks, factors such as time and competencies of students have to be considered all the time unlike in internship where the modules have been provided already and implementing the tasks is simply for the sake of compliance only. One participant wrote that student teaching is ideal while being in the field of teaching is being attached to reality.

"Student teaching was hard while real teaching is very hard" is the description written by one participant related to the first theme.

Theme 2: The first step to teaching is really full of challenges. The participants shared in their writing that 
the challenges they have encountered in their first month of teaching were more of the demands of teaching which included discipline of students, adjustment to teaching, paper works, high expectations and lack of motivating techniques and teaching strategies. Discipline included managing behavior of students such as their tantrums and being taciturn as identified by the Special Education teachers. Two BSE-Math graduates are not teaching in high school so they really need to adjust to the peculiarities of college and grade school teaching. Paper works such as quizzes, activities, seatworks and assignments that build up every day put pressure on the life of the new teachers. The respondents consider the high expectations of students, school administrators and parents to be challenging. Soft skills such as getting students' attention and teaching strategies add to their day to day challenges of dealing with students.

Theme 3. Some positive personal traits are essential to survive teaching. That patience is a virtue is indeed true in the teaching profession as this is the trait considered most important by the participants. Flexibility comes close to patience. The following comments capture this theme:

"Expect the unexpected and have patience and flexibility in every surprise you might encounter from your students".

"If you are not flexible, and don't want to become one, a piece of advice, QUIT while it's early". (this came from a Social Science major who is teaching Technology and Livelihood Education.)

“I should possess the attitude of being patient in doing lesson plans, syllabus and course outline”.

Theme 4. Teaching competencies are crucial in the practice of the teaching profession. The new teachers underscore the importance of communication skills particularly the use of conversational English because most of them are employed in English speaking schools. The English majors put premium on writing and reading skills since these are the skills they are developing among their students. Since the new teachers are struggling when it comes to student behavior, they regard classroom management skill to be important in their dealing with students. In one private school, one participant narrated that she uses the "class ticket" which is given to a student to warn him/her of misbehaviors inside the classroom. Indeed, Beutel and Croswell (2012) were right when they mentioned in their study that from behavior management stems all skills related to teaching such as having mastery of content, a repertoire of teaching methods and a variety of assessment techniques. The Special Education teachers are more adept at analyzing behavior problems since they know the intervention. Soft skills such as writing lesson plan, module and performance tasks following the Understanding by Design (UbD) framework are considered important competencies they have should have equipped from their college education. Diagnostic competence is also necessary in order to know students better and "start at where they are". As for the affective side, they value the importance of having acquired skills on time management and in having perseverance in handling students with special needs. One participant admitted her struggle dealing with a student with special needs in a mainstream class.

Theme 5: Lasallian education plays an important role in creating a positive attitude towards teaching. Guided by the vision-mission of De La Salle Lipa, the new teacher graduates realize its importance in the pursuit of the teaching profession. In relation to this theme, the following statements capsulized the participants' experiences:

"By putting the Lasallian vision-mission in whatever I do, I always remember that I'm here in Lasalle "to teach minds, touch hearts and transform lives" of my students".

“DLSL developed the passion in me since I honestly didn't choose BSE-English as my program but as years went on, I learned to be passionate about teaching and now I feel ready to face this field".

"Transformative education. Lifelong learning. Authentic learning. Teach them knowledge and skills. Season them with heart. Students aren't academic robots after all”. 
Macatangay, J.

Interestingly, some participants mentioned that at times when they feel like quitting because things get tough, they are reminded by the story of St. Lasalle who renounced his personal wealth just to establish schools for the poor.

\section{Conclusions}

Based on the narrative accounts of the respondents, this study found that there was a big difference between internship and real classroom teaching as affirmed by the participants. Differences are in terms of responsibilities, closer monitoring and guidance from the cooperating teacher, classroom tasks and on-the-spot problems. Though they valued their internship for two semesters prior to graduation, still they experienced "reality shock" in their first month of teaching. Conclusively, during their internship the students failed to lose sight of the forest to see the trees. This was similar to the reviewed study of Maat and Zakaria (2010) who found that in terms of preparation, novice teachers are more concerned on the delivery of their lessons while the experienced ones put more emphasis on the background of the students

Disciplining students, adjustment to teaching, paper works, high expectations from administrators, fellow teachers and parents, lack of motivating techniques and hurdling over what teaching strategies to use were some of the challenges encountered by the new teachers during their first month of teaching. Patience is the trait considered most important by the participants of the study; this was followed by flexibility.

The use of conversational English, managing the classroom well, writing lesson plans/modules and the skill to know students better were the competencies needed by the beginning educators as reflected in their responses to the given prompts. As for the affective component, they wanted to be equipped on the area of time management, achieve a persevering attitude and being adept at handling students with special needs in a mainstream class.

The charism of St. Lasalle has guided and improved the new teachers in creating a positive attitude towards teaching. They set St. Lasalle as their source of strength when they were about to give up because students were difficult to handle.

Indeed, the results of the study concur with the first stage known as Novices in Five Dreyfus Model Stages. The new educators have much to be learned about the dynamics of teaching so they need to develop continually in terms of pedagogical skills and professional knowledge that will enable them to move on to the next stage of the model.

Results of the study offer academic implications needed for improving current practices in teaching professional Education courses particularly on field study and internship. Likewise, findings from the study as revealed through the lived experience of the new teachers can serve as basis for enhancing the curriculum of the Education department of De La Salle Lipa to enhance the Lasallian graduate attributes.

\section{References}

Ball, D., \& Forzani, F. (2010). What does it take to make a teacher? Phi Delta Kappan, 92(2), 8-12. http://dx.doi.org/10.1177/003172171009200203

Bluestein, J. (2010). Becoming a win-win teacher survival strategies for the beginning educator. US: Sage.

Beutel, D., \& Croswell, L. (2012). Preparing to teach: Perceptions of graduate entry teacher education students. IAMURE: International Journal of Education, 2(1), 96-106.

De Gagne, J., \& Walters, K. (2010). The lived experience of online educators: hermeneutic phenomenology. MERLOT Journal of Online Learning and Teaching, 6(2), 357-366.

Friesen, N., Henriksson, C., \& Saevi, T. (Eds.). (2012). Hermeneutic phenomenology in education (pp. 1-37). Sense Publishers. http://dx.doi.org/10.1007/978-94-6091-834-6

Green, T. (2010). How to be successful your first year of teaching elementary school. US: Atlantic Publishing 
Group, Inc.

Kafle, N. (2011). Hermeneutic phenomenological research method simplified. Bodhi: An Interdisciplinary Journal, 5(1), 181-200.

Kakkori, L. (2009). Hermeneutics and phenomenology problems when applying hermeneutic phenomenological method in educational qualitative research. Paideusis, 18(2), 19-27.

Lichtman, M. (2006). Qualitative research in education: A user's guide. Thousand Oaks, CA: SAGE.

Maat S., \& Zakaria E. (2010). An exploration of mathematics teachers' reflection on their teaching practices. Asian Social Science, 6(5), 147-152.

Marchesani, R. (2007). The field guide to teaching: A handbook for new teachers. US: Pearson Education Ltd.

Thompson, J. (2009). The first-year teacher's checklist. San Francisco, CA: Jossey Bass.

Wallace, M., \& Irons, J. (2010). The lived experience of public school teachers: Novice to expert. National Social Science Journal, 33(2), 166-172. 
Macatangay, J. 